\title{
Factors influencing the recommendation of the Human Papillomavirus vaccine by South African doctors working in a tertiary hospital.
}

\author{
Muhammad Ehsanul Hoque
}

University of KwaZulu-Natal (Westville Campus) - Graduate School of Business and Leadership.

\begin{abstract}
Background: In South Africa, HPV vaccination programme has been incorporated recently in the school health system. Since doctors are the most trusted people regarding health issues in general, their knowledge and attitudes regarding HPV infections and vaccination are very important for HPV vaccine program nationally.

Objective: The objective of this study was to investigate factors contributing to recommendation of HPV vaccines to the patients.

Methods: This was a quantitative cross-sectional study conducted among 320 doctors, using a self-administered anonymous questionnaire.

Results: All the doctors were aware of HPV and knew that HPV is transmitted sexually. Their overall level of knowledge regarding HPV infections and HPV vaccine was poor. But the majority intended to prescribe the vaccine to their patients. It was found that doctors who knew that HPV 6 and 11 are responsible for $>90 \%$ of anogenital warts, their patients would comply with the counselling regarding HPV vaccination, and received sufficient information about HPV vaccination were 5.68, 4.91 and 4.46 times respectively more likely to recommend HPV vaccination to their patients, compared to their counterparts $(\mathrm{p}<0.05)$.
\end{abstract}

Conclusion: There was a knowledge gap regarding HPV infection and HPV vaccine among the doctors.

Keywords: Human Papillomavirus vaccine, South Africa.

DOI: http://dx.doi.org/10.4314/ahs.v16i2.26

Cite as: Hoque ME. Factors influencing the recommendation of the Human Papillomavirus vaccine by South African doctors working in a tertiary hospital. Afri Health Sci 2016;16(2): 567-575. http:/ / dx.doi.org/10.4314/ahs.v16i2.26

\section{Introduction}

Cervical cancer is a serious public health problem among women of reproductive age - even though it is preventable. It is the fourth most common cancer, and approximately 530,000 new cases and 275,000 deaths occur every year worldwide. Globally it is the second most common female cancer among women aged 15 to 44 years. ${ }^{1}$ In South Africa, it is estimated that 7,735 women are diagnosed with cervical cancer, and 4,248 die from the disease annually. Cervical cancer is the most common

$$
\begin{aligned}
& \text { Corresponding author: } \\
& \text { Muhammad Ehsanul Hoque, } \\
& \text { University of KwaZulu-Natal (Westville Campus)- } \\
& \text { Graduate School of Business and Leadership } \\
& \text { P.O.Box X54001 } 4000 \text { Durban, Durban } \\
& \text { KwaZulu-Natal 4000, South Africa } \\
& \text { T: +270312608690 } \\
& \text { F: +270312607679 } \\
& \text { Email:muhammad.ehsanul@gmail.com/ } \\
& \text { hoque@ukzn.ac.za }
\end{aligned}
$$

cancer among women aged 15 to 44 years, and the most common cancer among women in South Africa. ${ }^{2}$ Even though cervical cancer screening for women 30 years or older is free, the coverage is very low as $13.6 \% .^{2}$

It is known that cervical cancer is caused by persistent Human Papillomavirus (HPV) infection. There are many types of HPV, but HPV 16 and 18 are the main genotypes, as $70 \%$ of cervical cancers are caused by them and they are known as high-risk types. HPV 6 and 11 causes $90 \%$ of genital warts and are known as low-risk HPV. ${ }^{2}$ At any given time in South Africa, about 3.2\% of women in the general population are harbouring HPV-16 or 18 infection, and about $64 \%$ of invasive cervical cancers are attributed to HPV types 16 or $18 .^{2}$

There are two prophylactic HPV vaccines: quadrivalent and bivalent. Quadrivalent vaccine targets HPV types 6, 11,16 and 18, and a bivalent vaccine targets types 16 and 18. Both vaccines are commercially available. More than 100 countries in the world have been licensed to use one 
or both vaccines, and many countries have incorporated HPV vaccine into their routine vaccination programme. ${ }^{3}$ Many well-designed clinical trial studies conducted among 15 to 45 year-old women to investigate the safety and efficacy of the vaccines, have found that both vaccines had high efficacy and are safe. ${ }^{4-8}$ But there are still certain controversies about ethical issues, the long-term effects and complications. ${ }^{9-11}$ Another HPV vaccine named 9-valent has been developed by including HPV types 31, 33, 45, 52 and 58 to the quadrivalent vaccine. ${ }^{12}$ This nonavalent (9-valent) vaccine is currently under regulatory assessment for possible marketing authorization.

In the beginning, the HPV vaccines were licensed for females aged 9 to 26 years - to be given in three doses. ${ }^{13}$ These vaccines work best if administered before becoming sexually active. It has been shown that the vaccine's immunity lasts about seven years if the women concerned were not infected at the time of vaccination. ${ }^{14-16}$ Because of this, many countries recommend the administration of the vaccine to girls aged 11 to 14 years. ${ }^{8,17,18}$ According to $\mathrm{WHO}$, the recommended age group for HPV vaccination is girls aged 9 to 13 years - as the primary target population. ${ }^{12}$ Vaccination of older adolescent females or young women is recommended only if this is feasible, affordable, cost effective, and does not divert resources from vaccinating the primary target population or from effective cervical-cancer screening programmes. HPV vaccination of males is not recommended as a priority. ${ }^{19}$

With regard to vaccination schedule, WHO has changed its previous recommendation of a 3-dose schedule, to a 2 -dose schedule, For both the bivalent and quadrivalent HPV vaccines, a 2-dose schedule with a 6-month interval between doses, is recommended for females younger than 15 years. ${ }^{19}$ Those $>15$ years of age at the time of the second dose are also adequately covered by 2 doses. An interval no greater than $12-15$ months is suggested, in order to complete the schedule promptly - and before becoming sexually active. If the interval between doses is shorter than 5 months, a third dose should be given at least 6 months after the first dose. A 3-dose schedule $(0,1-2,6$ months $)$ is recommended for females aged 15 years and older, and for those known to be immune-compromised and/or HIV-infected (regardless of whether they are receiving antiretroviral therapy). ${ }^{19}$

Health-care workers (HCW) play a significant role in pa- rental decisions related to HPV vaccination. Many studies report that HCW are the most trusted, preferred and influential source of HPV vaccine information for adolescents and parents. ${ }^{20-22}$ There were mixed results reported regarding HCW recommendation of HPV vaccines - despite its importance. A study reported a 93-fold increase of HPV vaccination uptake because of HCW discussion and recommendation of $\mathrm{HPV}$ vaccination. ${ }^{23}$ Another study amongst physicians in Australia and Asia reported that about half of them have initiated conversations with patients and families about HPV vaccination. ${ }^{21,24}$

In South Africa, HPV vaccination was recently incorporated into the school health system. The first dose was carried out among grade four learners in April 2014. Another pilot study conducted among 39 school learners in KwaZulu-Natal province of South Africa, found that the vaccine completion rate was very high as $99.7 \%, 97.9 \%$ and $97.8 \%$ for the first, second and third doses respectively. ${ }^{25}$ Doctors' knowledge and attitudes are very important as it influences parents' decisions about vaccine acceptability. No previous studies in South Africa have been conducted among doctors to investigate their knowledge and attitudes regarding HPV vaccination. Therefore, this study seeks to investigate doctors' knowledge, attitudes and recommendations, regarding HPV vaccination.

\section{Materials and methods}

This was a quantitative cross-sectional study conducted among doctors who were employed permanently at the Dr George Mukhari Hospital (DGMH). The hospital is a referral hospital for Polokwane in the NorthWest Province of South Africa, but is situated about $35 \mathrm{~km}$ north of South Africa's capital city Pretoria, in Gauteng Province. Currently there are about 1000 doctors working in this hospital which has 39 wards and 1400 beds. Although a teaching hospital, it also provides out-patient treatment to its catchment population.

The minimum sample size for the study was calculated to be 270 , this based on the following information: assuming $50 \%$ of doctors have enough knowledge regarding HPV vaccination, with a $95 \%$ confidence level and $80 \%$ power of the study. For uncompleted questionnaires, 20\% more were added to the sample size, and thus the final sample size was 324 doctors. Sampling techniques, data collection, and questionnaire developments were well explained elsewhere. ${ }^{26}$ Doctors working in the intensive care unit 
and laboratory workers were excluded from the study. Data collection took place between March and June 2013. The Medunsa Research Ethics Committee of the University of Limpopo and the hospital management team approved the study. The research assistant informed all participants about the study before they signed the consent form and completed the questionnaire. Their confidentiality and anonymity was maintained at all times.

Demographic variables were summarized using descriptive statistics such as mean (SD) for continuous variables and percentages for categorical variables. $\chi^{2}$-test or Fishers' exact test was used to compare categorical variables. Stepwise binary logistic regression models were carried out to determine variables that were significantly associat- ed with recommending HPV vaccination to the patients. $P$ values less than 0.05 were considered to be statistically significant.

\section{Results}

A total of 325 questionnaires were distributed and 320 completed questionnaires were received. With regard to participants' socio-demographic information, just over half of them were younger than 40 years - as the average age was 39 years with a standard deviation of 8 years. Most participants were female $(78 \%)$ and medical officers $(87 \%)$. About half of respondent $(47.5 \%)$ had more than 10 years of working experience and $30.9 \%$ were working for more than 7 hours a week in an out-patient department (see Table 1).

Table 1: Respondents provider and practice characteristics

\begin{tabular}{|c|c|c|}
\hline Variable & Frequency & Percent \\
\hline \multicolumn{3}{|l|}{ Gender } \\
\hline Female & 250 & 78.1 \\
\hline Male & 70 & 21.9 \\
\hline \multicolumn{3}{|l|}{ Age group } \\
\hline less than 30 years & 35 & 10.9 \\
\hline $30-39$ years & 137 & 42.8 \\
\hline $40-49$ years & 101 & 31.6 \\
\hline 50 years or above & 47 & 14.7 \\
\hline Average age (SD) & \multicolumn{2}{|c|}{39.33 years $(8.41)$} \\
\hline \multicolumn{3}{|l|}{ Profession } \\
\hline Medical Officer & 277 & 86.6 \\
\hline Intern & 43 & 13.4 \\
\hline \multicolumn{3}{|l|}{ Years of Experience } \\
\hline Less than 10 years & 168 & 52.5 \\
\hline $10-19$ years & 114 & 35.6 \\
\hline 20 years or more & 38 & 11.9 \\
\hline Mean years of experience (SD) & \multicolumn{2}{|c|}{10.16 years $(7.04)$} \\
\hline \multicolumn{3}{|c|}{ Hours spending in direct patient care per week } \\
\hline Less than 7 hours & 221 & 69.1 \\
\hline 7 or more hours & 99 & 30.9 \\
\hline
\end{tabular}


With regards to doctors' knowledge about HPV infection and HPV vaccine, all the doctors were aware of HPV and they knew that HPV was transmitted sexually as well as HPV infection is the main cause for cervical cancer. Table 2 summarises doctors' knowledge regarding HPV infections and the HPV vaccine. More than half of the doctors (59.4\%) did not know that HPV is the most common sexually transmitted infection. Only 31\% doctors knew that conventional screening HPV tests have a sensitivity of $>75 \%$. The majority knew that $>80 \%$ of the population harbours HPV $(75.3 \%)$ and persistent HPV infection is a necessary cause of cervical cancer (94.7\%). None of the doctors knew that a regular Pap test with a frequency of $\leq 3$ years reduces the risk of cervical cancer between $71 \%$ and $90 \%$ and between $60 \%$ to $80 \%$ cervical cancer is caused by HPV-16 and -18. More than half of the doctors $(59.4 \%)$ could not name both the vaccines and $75.3 \%$ did not know the effectiveness of the vaccines. Overall, the knowledge scores were low among the doctors as their average score was $5.11(\mathrm{SD}=1.29)$ out of 11 questions where each questions was allocated one point for correct answers.

Table 2: Doctors' Knowledge regarding the HPV Infection and HPV Vaccine (n $=320)$

\begin{tabular}{|c|c|c|c|c|c|}
\hline Knowledge (correct answer) & \multicolumn{2}{|c|}{$\begin{array}{l}\text { I will prescribe the HPV } \\
\text { vaccine to my patients }\end{array}$} & Total & $\begin{array}{l}\text { Chi- } \\
\text { squared } \\
\text { value }\end{array}$ & p-value \\
\hline $\begin{array}{l}\text { HPV is the most common sexually } \\
\text { transmitted infection }\end{array}$ & $5(41.7 \%)^{\#}$ & $128(41.6 \%)$ & $133(41.6 \%)$ & 0.000 & 0.994 \\
\hline $\begin{array}{l}\text { Persistent HPV infection is a necessary } \\
\text { cause of cervical cancer }\end{array}$ & $11(91.7 \%)$ & $292(94.8 \%)$ & $303(94.7 \%)$ & 0.226 & 0.634 \\
\hline $\begin{array}{l}\text { Conventional screening HPV test have } \\
\text { a sensitivity of }>75 \%\end{array}$ & $7(58.3 \%)$ & $92(29.9 \%)$ & $99(30.9 \%)$ & 4.379 & 0.042 \\
\hline There are 13 to $17 \mathrm{HPV}$ types & $1(8.3 \%)$ & $72(23.4 \%)$ & $73(22.8 \%)$ & 1.484 & 0.223 \\
\hline $\begin{array}{l}\text { HPV } 6 \text { and } 11 \text { are responsible for }> \\
90 \% \text { of anogenital warts }\end{array}$ & $8(66.7 \%)$ & $276(89.6 \%)$ & $284(88.8 \%)$ & 6.090 & 0.035 \\
\hline $\begin{array}{l}\text { A regular Pap test with a frequency of } \leq \\
3 \text { years reduces the lifetime risk of } \\
\text { cervical } \\
\text { cancer by } 71-90 \%\end{array}$ & $0(0.0)$ & $0(0.0)$ & $0(0.0)$ & & \\
\hline The vaccines are very effective & $0(0.0 \%)$ & $79(25.6 \%)$ & $79(24.7 \%)$ & 4.747 & 0.032 \\
\hline Overall mean (SD) & $4.83(1.40)$ & $5.12(1.28)$ & $5.11(1.29)$ & 0.756 & $0.450^{*}$ \\
\hline
\end{tabular}

*According to t-test., ${ }^{*}$ column percentage 
Doctors' attitudes concerning HPV immunization, perceived support, expected benefits and intention to recommend vaccination, are shown in table 3 (below). Only one doctor agreed that the vaccines should be given to girls before they become sexually active. Less than half (45\%) of the doctors reported that the best age for a universal immunization programme would be less than 14 years.
All the doctors reported that physicians will recommend HPV vaccination. Almost all the participants agreed that parents will accept HPV vaccination for their children; that adolescents and young adults will accept HPV vaccination; that parents will prefer HPV vaccination to be given at school; that a vaccination programme will reduce the frequency of screening in vaccinated women, and also reduce the number of post-screening follow-up interventions $(>97 \%)$.

Table 3. Doctors' attitudes concerning HPV immunization, perceived support, expected benefits, and intention to recommend vaccination $(\mathbf{n}=\mathbf{3 2 0})$

\begin{tabular}{|c|c|c|c|c|c|}
\hline \multirow[t]{2}{*}{$\begin{array}{c}\text { Statements (doctors agree with the } \\
\text { statement) }\end{array}$} & \multicolumn{2}{|c|}{$\begin{array}{c}\text { I will prescribe the HPV vaccine } \\
\text { to my patients }\end{array}$} & \multirow[t]{2}{*}{$\begin{array}{c}\text { Total } \\
(\mathbf{n}, \%)\end{array}$} & \multirow{2}{*}{$\begin{array}{l}\text { Chi- } \\
\text { squared } \\
\text { value }\end{array}$} & \multirow[t]{2}{*}{ p-value } \\
\hline & $N o(n, \%)$ & $\operatorname{Yes}(n, \%)$ & & & \\
\hline \multicolumn{6}{|l|}{ HPV vaccine should be given } \\
\hline Before sexually active lifestyles & $0(0.0)$ & $1(0.3)$ & $1(0.3)$ & 0.039 & 0.843 \\
\hline $\begin{array}{l}\text { The best age for an eventual } \\
\text { immunization programme would be } \\
<14 \text { years }\end{array}$ & $8(66.7)$ & $136(44.2)$ & $144(45.0)$ & 2.706 & 0.439 \\
\hline \multicolumn{6}{|l|}{$\begin{array}{l}\text { A vaccination programme would } \\
\text { eventually permit }\end{array}$} \\
\hline Beginning screening later in life & $12(100.0)$ & $302(98.1)$ & $314(98.1)$ & 0.238 & 0.625 \\
\hline $\begin{array}{l}\text { Reduction of the frequency of } \\
\text { screening interventions in } \\
\text { vaccinated females }\end{array}$ & $12(100.0)$ & $300(97.4)$ & $312(97.5)$ & 0.320 & 0.572 \\
\hline $\begin{array}{l}\text { Reduction of the number of post- } \\
\text { screening }\end{array}$ & $12(100.0)$ & $299(97.1)$ & $311(97.2)$ & 0.361 & 0.548 \\
\hline The abolishment of screening & $12(100.0)$ & $289(93.8)$ & $301(94.1)$ & 0.787 & 0.375 \\
\hline \multicolumn{6}{|l|}{ In your opinion most } \\
\hline $\begin{array}{l}\text { Physicians will recommend HPV } \\
\text { vaccination to their patients }\end{array}$ & $12(100.0)$ & $308(100.0)$ & $320(100.0)$ & & \\
\hline $\begin{array}{l}\text { Parents will accept HPV vaccination } \\
\text { for their children }<14 \text { years of age }\end{array}$ & $12(100.0)$ & $301(97.7)$ & $313(97.8)$ & 0.279 & 0.597 \\
\hline $\begin{array}{l}\text { Parents will prefer HPV vaccination } \\
\text { to be given at school }\end{array}$ & $12(100.0)$ & $302(98.1)$ & $314(98.1)$ & 0.238 & 0.625 \\
\hline $\begin{array}{l}\text { Adolescents and young adults will } \\
\text { accept HPV vaccination }\end{array}$ & $12(100.0)$ & 307 (99.7) & $319(99.7)$ & 0.039 & 0.843 \\
\hline $\begin{array}{l}\text { Adolescents and young adults will } \\
\text { seek HPV vaccination }\end{array}$ & $12(100.0)$ & $304(98.7)$ & $316(98.8)$ & 0.158 & 0.691 \\
\hline \multicolumn{6}{|l|}{$\begin{array}{l}\text { Your patients will comply with } \\
\text { counsel regarding }\end{array}$} \\
\hline Safe sexual behaviour & $0(0.0)$ & $7(2.3)$ & $7(2.2)$ & 0.279 & 0.597 \\
\hline $\begin{array}{l}\text { Regular screening for cervical } \\
\text { cancer }\end{array}$ & $1(8.3)$ & $21(6.8)$ & $22(6.9)$ & 0.041 & 0.893 \\
\hline HPV vaccination & $8(66.7)$ & $271(88.0)$ & $279(87.2)$ & 4.700 & 0.030 \\
\hline
\end{tabular}


Overall, most $(96.3 \%)$ of the doctors mentioned that they will recommend the vaccines to their patients. Factors that contribute in terms of recommending HPV vaccination are shown in Table 4 (below). Backward stepwise binary logistic regression analysis was carried out to find the significant predictor for recommending HPV vaccination to the patients. Initially all those variables that were significantly associated with prescribing HPV vaccination to the patient were included in the model. The Hosmer and Lemeshow test indicated that the model fitted adequately (Chi-square $=4.159, \mathrm{p}=0.385)$. The classification table showed that overall the model predicted $96.3 \%$ accurately. The results showed that doctors who mentioned that HPV 6 and 11 are responsible, comply with HPV vaccination, and information received about $H P V$ vaccination - were $5.677,4.907$ or 4.458 times, respectively, more likely to recommend HPV vaccination to their patients compared to their counterparts $(p<0.05)$.

\section{Table 4: Backward stepwise binary logistic regression output for recommending HPV vaccination by medical doctors in South Africa $(\mathbf{n}=\mathbf{3 2 0})$}

\begin{tabular}{|c|c|c|c|c|c|}
\hline \multicolumn{2}{|c|}{$\begin{array}{ll}\text { Variable } \\
\end{array}$} & \multirow{3}{*}{\begin{tabular}{|c|}
$\begin{array}{c}\text { Odds } \\
\text { ratio (OR) }\end{array}$ \\
.294
\end{tabular}} & \multicolumn{2}{|c|}{$\begin{array}{c}\text { 95\% C.I. for } \\
\text { OR }\end{array}$} & \multirow{3}{*}{$\begin{array}{c}\begin{array}{c}\text { p- } \\
\text { value }\end{array} \\
.052\end{array}$} \\
\hline & & & \multirow{2}{*}{$\frac{\text { Lower }}{.085}$} & \multirow{2}{*}{$\frac{\text { Upper }}{1.011}$} & \\
\hline Step $1^{\mathrm{a}}$ & Conventional screening of HPV test & & & & \\
\hline & HPV 6 and 11 are responsible & 5.413 & 1.338 & 21.906 & .018 \\
\hline & Comply with HPV vaccination & 4.784 & 1.193 & 19.180 & .027 \\
\hline & $\begin{array}{c}\text { Information received so far about } \mathrm{HPV} \\
\text { vaccination }\end{array}$ & 4.130 & 1.082 & 15.767 & .038 \\
\hline & Time spent in direct patient care per week & .802 & .215 & 2.992 & .742 \\
\hline & Constant & 1.303 & & & .820 \\
\hline \multirow[t]{5}{*}{ Step $2^{\mathrm{a}}$} & Conventional screening of HPV test & .290 & .084 & .998 & .050 \\
\hline & HPV 6 and 11 are responsible & 5.677 & 1.439 & 22.395 & .013 \\
\hline & Comply with HPV vaccination & 4.907 & 1.233 & 19.523 & .024 \\
\hline & $\begin{array}{l}\text { Information received so far about HPV } \\
\text { vaccination }\end{array}$ & 4.458 & 1.262 & 15.750 & .020 \\
\hline & Constant & 1.078 & & & .941 \\
\hline
\end{tabular}

a. Variable(s) entered on step 1: Conventional screening of HPV test; HPV 6 and 11 are responsible; Comply with HPV vaccination; Information received so far about HPV vaccination; Time spent in direct patient care per week.

\section{Discussion}

This is the first quantitative study conducted among medical doctors in South Africa to investigate their knowledge, attitudes and recommendations about HPV vaccination to their patients. Overall, the level of knowledge regarding HPV infections and vaccination among the medical doctors was low, but the HPV vaccine recommendation was very high. All the doctors in the study were aware of HPV, and they knew HPV was transmitted sexually and that HPV infection causes cervical cancer. Many of the respondents did not know that HPV is the most common sexually transmitted infection and that the conventional screening HPV test has a sensitivity of $>75 \%$. It was surprising that none of the doctors knew that the regular Pap smear test reduces the risk of cervical cancer by $71 \%$ to $90 \%$ and that $60 \%$ to $80 \%$ of cervical cancer is caused by HPV-16 and -18. More than half of the doctors could not name both the vaccines, and $75.3 \%$ did 
not know the effectiveness of the vaccines. With regard to knowledge about HPV infections and vaccines, studies have reported various levels of knowledge among physicians. For example, a recent study conducted among pediatricians in Serbia, reported insufficient knowledge of HPV infection and the HPV vaccine. ${ }^{27}$ A Jordanian study assessed the knowledge and attitudes of obstetricians and gynecologists towards HPV infection and its vaccine, and found that the vast majority knew about most of the facts relating to HPV infection. ${ }^{28}$ Among Nigerian HCW, 91\% were aware of HPV - but only $44.0 \%$ were aware of the HPV vaccine. ${ }^{29}$ A Cross-Sectional Study conducted among Primary Care Physicians in Hong Kong found a low level of knowledge with regard to the epidemiology of HPV infection. ${ }^{30}$

HCW recommendations have a significant impact on the acceptability of the vaccines - as they are the most trusted people. With regard to recommending HPV vaccines, all the doctors agreed to recommend the vaccines to their patients. This finding is consistent with a national survey of pediatricians and family practice physicians in the USA, which found that $98 \%$ of pediatricians and $88 \%$ of family practice physicians reported offering HPV vaccine to their female patients. ${ }^{31}$ Another study from the USA reported about $33 \%$ of physicians offering the HPV vaccine routinely to their eligible patients. ${ }^{32}$ Investigations of the awareness and attitudes about the HPV vaccines among pediatricians, obstetricians and gynecologists in Turkey, showed that HPV vaccines were recommended by $59.4 \%, 82.6 \%, 66.7 \%$ and $80.6 \%$ of pediatricians, OBG specialists, $\mathrm{OBG}$ residents and pediatric residents, respectively. ${ }^{33}$ High acceptability of the HPV vaccine was found among French general practitioners and the acceptability rate increased from $79.9 \%$ to $87.1 \%$ between the years 2007 and $2010 .^{34}$ Other studies have also reported similar findings among health-care workers. ${ }^{31,35-37}$

The present study showed that all the doctors - except one - disapproved of giving the vaccine before becoming sexually active. This finding is very discouraging, as doctors are the main driver for the high uptake of HPV vaccination among adolescents. This is in contrast with other studies conducted elsewhere. Most Jordanian obstetricians and gynecologists (78\%) indicated that the vaccine should be given to girls before they became sexually active. ${ }^{28}$ But $39 \%$ of Asian physicians did not approve
HPV vaccination to girls before the onset of sexual activity. ${ }^{21}$ Our study was conducted before the implementation of HPV vaccination nationally through the school health system in the year 2014. Doctors' knowledge about vaccine safety and efficacy was low in this study.

The recommended HPV vaccination age varies considerably throughout the world among HCW. Doctors in this study were asked to indicate the best age for vaccination. Less than half indicated that $<14$ years was the best time for HPV vaccination. This finding is similar to a study among primary care physicians in Hong Kong (45.6\%). ${ }^{30}$ An American study highlighted that most pediatricians recommended HPV vaccines to girls aged 16 to 18 years, while another study indicated that fewer physicians and pediatricians recommended HPV vaccines for children aged 11 to 12 years than for older female adolescents. ${ }^{31,38}$ Another study conducted in England found that doctors' recommendation to vaccinate increased as the age of the vaccination increases. ${ }^{39}$ This might have a significantly negative impact on vaccination coverage nationally.

This study had some limitations. First, it was a crosssectional study. Therefore a causal relationship could not establish a relationship between doctors' knowledge or attitudes and their HPV prescriptions. This study was conducted in one institution, and thus generalisation of results is not possible. The self-reported data is subject to bias, but anonymity of the questionnaire may have minimised this. This study has revealed doctors' knowledge and attitudes regarding HPV infections and HPV vaccination. The findings should motivate further studies and they will be helpful for programme and policy development on HPV immunisation and the prevention of cervical cancer in South Africa.

\section{Conclusion}

South African doctors' overall knowledge of HPV infection and vaccines was poor, but there was very high acceptability to recommend the vaccine to their patients. Doctors who knew that HPV 6 and 11 are responsible for $>90 \%$ of anogenital warts, whose patients comply with the counseling regarding HPV vaccination, and who received sufficient information about HPV vaccination - were more likely to recommend HPV vaccination to their patients. There is a need for health education on safety and efficacy and the best time for HPV vaccination 
among the doctors and the general public, in order to reduce the burden of cervical cancer and to enhance the benefit of this preventative tool.

\section{Acknowledgements}

I wish to thank all the doctors who voluntarily took time to complete the questionnaire. I would also like to acknowledge NRF for providing funding to present the finding of this study in an international conference

\section{Conflict of interest}

None declared.

\section{References}

1. Bruni L, Barrionuevo-Rosas L, Albero G, et al. ICO Information Centre on HPV and Cancer (HPV Information Centre). Human Papillomavirus and Related Diseases in the World. Summary Report 2015-04-08. PubMed Available at: http://www.hpvcentre.net/summaryreport. php (Accessed 12/08/2015)

2. Bruni L, Barrionuevo-Rosas L, Albero G, et al. ICO Information Centre on HPV and Cancer (HPV Information Centre). Human Papillomavirus and Related Diseases in South Africa. Summary Report 2014-12-18. PubMed Available at: http://www.who.int/ hpvcentre. (Accessed 15/01/2015)

3. Markowitz LE, Tsu V, Deeks SL, et al. 2012. Human papillomavirus vaccine introduction - the first five years. Vaccine 2012; 30:F139-48.

4. Smith JS, Lindsay L, Hoots B, et al. Human papillomavirus type distribution in invasive cervical cancer and high-grade cervical lesions: a meta-analysis update. Int J Cancer 2007;121(3):621-32.

5. Lu B, Kumar A, Castellsague X, et al. Efficacy and safety of prophylactic vaccines against cervical HPV infection and diseases among women: a systematic review \& meta-analysis. BMC Infect Dis 2011;11:13.

6. Giuliano AR, Palefsky JM, Goldstone S, et al. Efficacy of quadrivalent HPV vaccine against HPV infection and disease in males. N Engl J Med 2011;364(5):401-11.

7. Palefsky JM, Giuliano AR, Goldstone S, et al. HPV vaccine against anal HPV infection and anal intraepithelial neoplasia. N Engl J Med 2011;365(17):1576-85.

8. Markowitz LE, Dunne EF, Saraiya M, et al. Centers for Disease Control and Prevention (CDC); Advisory Committee on Immunization Practices (ACIP). Quadrivalent Human Papillomavirus Vaccine. Recommendations of the Advisory Committee on Immunization Practices (ACIP). MMWR Recomm Rep 2007; 56(RR02).

9. Javitt G, Berkowitz D, Gostin LO. Assessing mandatory HPV vaccination: who should call the shots. J Law Med Ethics 2008;36:384-95.

10. Rothman SM, Rothman DJ. Marketing HPV vaccine: implications for adolescent health and medical professionalism. JAMA 2009; 302:781-86.

11. Intlekofer KA, Cunningham MJ, Caplan AL. The HPV vaccine controversy. Virtual Mentor 2012;14:39-49.

12. Dochez C, Bogers JJ, Verhelst R, Rees H. HPV vaccines to prevent cervical cancer and genital warts: an update. Vaccine, 2014;32:1595-1601.

13. Centers for Disease Control and Prevention. FDA licensure of bivalent human papillomavirus vaccine (HPV2, Cervarix) for use in females and updated HPV vaccination recommendations from the Advisory Committee on Immunization Practices (ACIP). MMWR Morb Mortal Wkly Rep 2010;59(20):626-29.

14. De Carvalho N, Teixeira J, Roteli-Martins CM, et al. Sustained efficacy and immunogenicity of the HPV$16 / 18$ AS04-adjuvanted vaccine up to 7.3 years in young adult women. Vaccine 2010;28(38):6247-55.

15. Mariani L, Venuti A. HPV vaccine: an overview of immune response, clinical protection, and new approaches for the future. J Transl Med 2010;8:105.

16. RomanowskiB. Long term protection against cervical infection with the human papillomavirus: review of currently available vaccines. Hum Vaccin 2011;7:161-69.

17. Black LL, Zimet GD, Short MB, et al. Literature review of human papillomavirus vaccine acceptability among women over 26 years. Vaccine 2009;27:1668-73. 18. Centers for Disease Control and Prevention (CDC). Recommendations on the use of quadrivalent human papillomavirus vaccine in males - Advisory Committee on Immunization Practices (ACIP). MMWR Morb Mortal Wkly Rep 2011;60(50):1705.

19. World Health Organisation (WHO). Human papillomavirus vaccines: WHO position paper, October 2014. Available at: http://www.who.int/immunization/diseases/hpv/en/ (Accessed on 12 August 2015).

20. Pitts M, Smith A, Croy S, et al. Singaporean women's knowledge of human papillomavirus (HPV) and attitudes toward HPV vaccination. Women Health 2009;49(4):334 -51 .

21. Chow SN, Soon R, Park JS, et al. Knowledge, attitudes, and communication around human papillomavirus 
(HPV) vaccination amongst urban Asian mothers and physicians. Vaccine 2010;28(22):3809-17.

22. Hopkins TG, Wood N. Female human papillomavirus (HPV) vaccination: global uptake and the impact of attitudes. Vaccine 2013;31:1673-79.

23. Rosenthal SL, Weiss TW, Zimet GD, et al. Predictors of HPV vaccine uptake among women aged 19-26: importance of a physician's recommendation. Vaccine 2011;29(5):890 -95.

24. Tan J, Farrell L, Allen DG. The attitudes of Australian gynaecologists to HPV vaccination: an ASCCP survey. Aust N Z J Obstet Gynaecol 2010;50(5):472-77.

25. Moodley I, Tathiah N, Mubaiwa V, Denny L. High uptake of Gardasil vaccine among 9-12-year-old schoolgirls participating in an HPV vaccination demonstration project in KwaZulu-Natal, South Africa. S Afr Med J 2013;103:313-317.

26. Hoque ME, Monokoane S, Van Hal G. 2014. Knowledge of and attitude towards human papillomavirus infection and vaccines among nurses at a tertiary hospital in South Africa. J Obstet Gynaecol 2014;34:182-86.

27. Nikolic Z, Matejic B, Kesic V, et al. Factors influencing the recommendation ofthe Human Papillomavirus vaccine by Serbian pediatricians. I Pediatr Adolesc Gynecol 2015;28:12-18.

28. Lataifeh I, Obeidat N, Al-Mehaisen L, et al. A survey of Jordanian obstetricians and gynecologists' knowledge and attitudes toward human papillomavirus infection and vaccination. Eur J Gynaecol Oncol 2014;35(4):429-32.

29. Audu BM, Bukar M, Ibrahim AI, et al. Awareness and perception of human papilloma virus vaccine among healthcare professionals in Nigeria. J Obstet Gynaecol 2014; 34(8):714-17.

30. Wong MCS, Lee A, Ngai KLK, et al. Knowledge, attitude, practice and barriers on vaccination against human papillomavirus infection: a cross-sectional study among primary care physicians in Hong Kong. PLOS ONE 2013;8(8): e71827.
31. Daley MF, Crane LA, Markowitz LE, et al. Human papillomavirus vaccination practices: a survey of US physicians 18 months after licensure. Pediatrics 2010;126(3):425-33.

32. Bruno DM, Wilson TE, Gany F, et al. 2014. Identifying human papillomavirus vaccination practices among primary care providers of minority, low-income and immigrant patient populations. Vaccine 2024;32:4149-54.

33. Tolunay O, Celik U, Karaman SS, et al. Awareness and attitude relating to the human papilloma virus and its vaccines among pediatrics, obstetrics and gynecology specialists in Turkey. Asian Pac J Cancer Prev 2014;15(24):1072328.

34. Lasset C, Kalecinski J, Re' gnier V, et al. Practices and opinions regarding HPV vaccination among French general practitioners: evaluation through two cross-sectional studies in 2007 and 2010. Int J Public Health 2014; 59:51928.

35. Ko EM, Missmer S, Johnson NR. Physician attitudes and practice toward human papillomavirus vaccination. $J$ Low Genit Tract Dis 2010;14:339-45.

36. Young JL, Bernheim RG, Korte JE, et al. Human papillomavirus vaccination recommendation may be linked to reimbursement: a survey of Virginia family practitioners and gynecologists. J Pediatr Adolesc Gynecol 2011;24:38085.

37. Post RE, Carek PJ, Mainous Iii AG, et al. Factors affecting HPV vaccine useamong recent family medicine residency graduates. Fam Med 2013;45:90-94.

38. Daley MF, Liddon N, Crane LA, et al. A national survey of pediatrician knowledge and attitudes regarding human papillomavirus vaccination. Pediatrics 2006;118:2280-89. 39. Lutringer-Magnin D, Kalecinski J, Barone G, et al. Human papillomavirus (HPV) vaccination: perception and practice among French general practitioners in the year since licensing. Vaccine 2011;29:5322-28. 